\title{
Whether or Not a Woman Has a Family Plan Is an Important Cause of Gender Discrimination in the Labor Market?
}

\begin{abstract}
Hanzhang $\mathrm{Su}$
Guangdong Experimental High School AP International Curriculum, Guangzhou, Guangdong 510375, China, happysu0416@163.com

ABSTRACT

This paper focuses on the hiring bias relative with future children plan among men and women. Through sending 400 virtual resumes to 50 enterprise, the paper analyses the difference of callback rate between the four types of resumes, men with and without children plan in the next 5 years, and women with and without children plan in the next 5 years. The conclusion of the experience is that children plan makes significant difference on hiring bias, especially on women. Although such phenomenon may be hard to change, but it worth attention for that it may interrupt the government's birth control policy, exacerbate the aging of the population and bring more pressure to the society.
\end{abstract}

Keywords: hiring bias, children plan, birth control policy.

\section{INTRODUCTION \& LITERATURE REVIEW}

In real-life decision situations we are often faced with discrimination in various aspects. For example, people easily experience sexual orientation bias in the social network and racism when walking in the street. Among these, employment discrimination is one of the most discussed, for that it is so common in the current society, and it relates to almost everyone's life and death. According to EEOC, which refers to U.S. Equal Employment Opportunity Commission, the following situations are all counted as employment discrimination: unfair treatment, harassment, denial of a reasonable workplace change, improper questions about or disclosure of genetic information or medical information and retaliation [1]. There was even research that proved the existence of body weight bias in hiring decision [2]. However, even with the laws and organizations preventing employment bias, it is still happening everywhere among the world and putting people into struggles. It has been widely noticed that gender, just as other identities, are posting serious influence in employment discrimination. Research from Bosak and Sczesny has revealed that "gender bias are evident in the screening and hiring stage of the personnel selection process" [3]. Similarly, in Using Independent Bernoulli
Random Variables to Model Gender Hiring Practices by Hildebrand, simulations also provided evidence of gender bias in the employing process [4]. Such discrimination has a strong history support—women were not supported to work as today decades ago. A comparison in job participation rate clearly reveals this: in 1950, the overall participation rate of women was 34 per- cent, while the number was raised to 60 in 2000. Even in the current year, 2019, the worldwide ratio of female to male labor force participation rate estimate is 66.691 per-cent, which is quite severe. In some countries, the number even falls below 30 [5]. In America, it was not until the World War II that the number of women working dramatically raise [6]. What is causing the discrimination to continue even after years of the women's movement and the sexual revolution? Previous researches gave out answers including masculine corporate [7], "male sex-typed jobs", etc. From the recent discussion on the topic based on the three-child policy in China that was announced already passed law formally [8], future children plan is considered to be one of the most significant gender hiring biases in the current labor market as well. Discussions reveals that companies may reject women for having children plan in future. Such hiring bias should be attached with attention, because such rejection may resulted in women refusing children plan for job opportunity. Together with the current 18.7 percent people being over 60 , the gender hiring bias 
relative with children plan could make the aging population in China worse and damaging the effect of years of birth control policy [9]. In addition, from existing researches, it is easy to imply on the positive effect of eliminating gender hiring bias. For example, according to a 2019 paper, balancing gender representation in candidate states are able to "correct biases for some professions where the world distribution is skewed" [10]. This paper focuses on the examination whether children plan exists as an gender hiring bias in the labor market and the relative impact of the bias on the society.

\section{METHOD}

Under the context of Chinese labor market, this paper describes the experiment trying to look into the gender bias in hiring, researching whether or not a woman has a family plan could be a determinate cause of gender discrimination in the labor market, with the method of field study. The experiment consisted of two phases. During the first phase, there were 400 virtual resumes generated. The 400 resumes were evenly sorted into four categories: female or male with or without a statement of "No plan to have a child in 5 years." Except the statement, all other aspects on the resumes were strictly controlled. To avoid the confounding bias, all the generated resumes contained information including heights varied from 1.55 meters to 1.75 meters, BMIs varied from 18.5 to 24 (a relatively healthy stage), education background uniformly of undergraduate, marital status uniformly of single and childless, and health status uniformly without serious illness. Other unmentioned aspects required on the resume would also be the same or at least similar. In the second phase, the resumes were delivered targeting top 50 enterprises in the field of real estate sales in Shanghai. There were two ways of delivering the resumes: one by filling forms at specific websites provided by the company and the second way was submitting free formatting resumes. For the resumes that clearly stated no children plan, the statement of "No plan to have a child in 5 years" was either filled in the self-evaluation part of the form provided or an obvious place in the free formatting resume. The CVs were sent out to the companies on the same date for the same job openings and the callback rates were measured. Once the companies call back, they will be explained about the experiment so that they can understand that there is no real person referring to the resume they receive. The experiment carried for 3 months, so any call back after three months the CVs were sent wasn't considered in the callback rates. The independent variables in the study will be genders and whether with or without the statement, and the dependent variable will be the callback rate solely. The existence of the employment bias was determined by whether the callback rates of the two different groups have significant differences.

\section{RESULT}

\section{callback numbers}

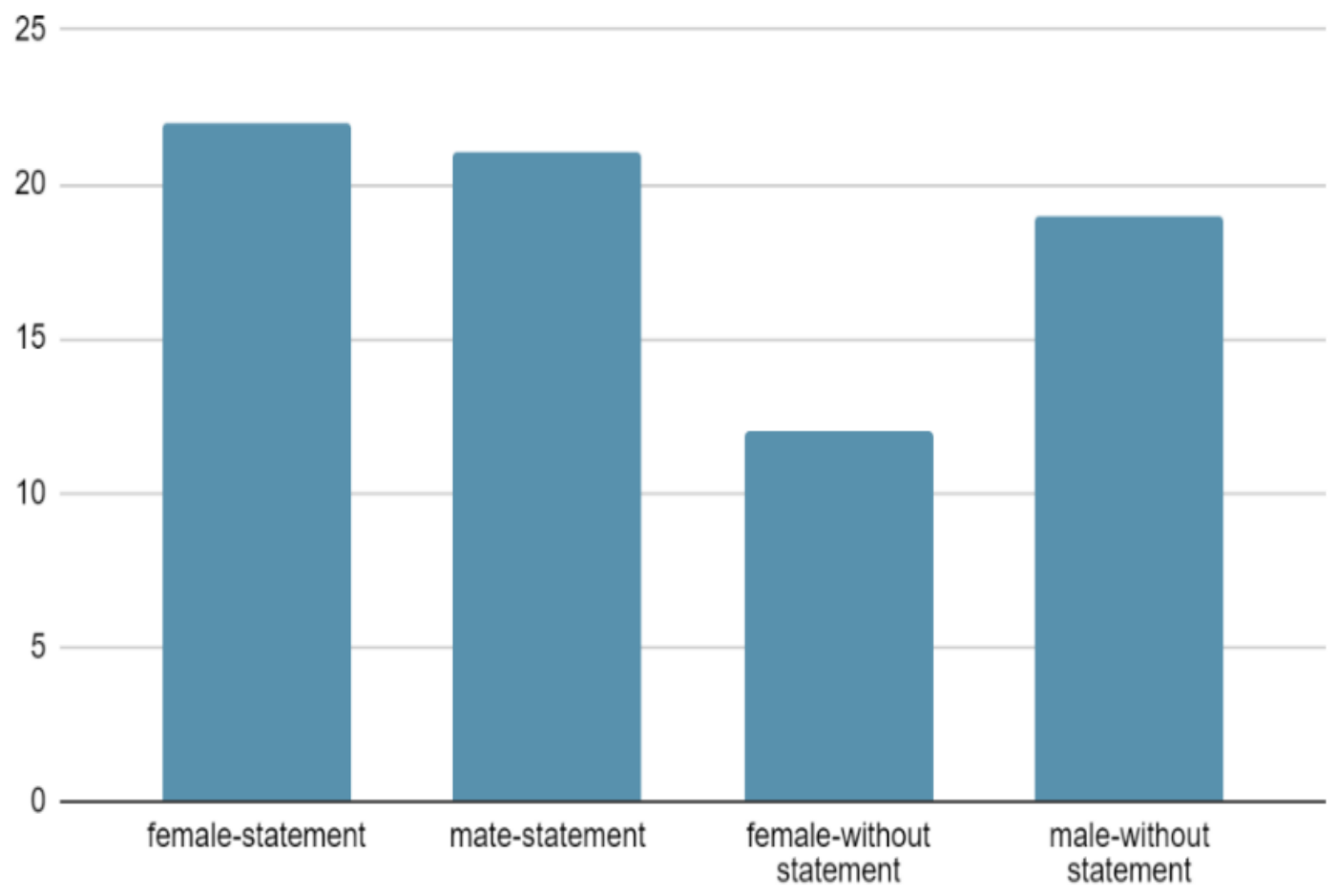

Figure 1 Predicted Result 1 
As shown in the Figure 1, he resumes that were categorized into male and without the statement of "No plan to have a child in 5 years" recorded 21 callbacks out of the 100 resumes sent, which had a callback rate of 21 per-cent. Compared to those, the callback rate of the resumes of male and with the statement of "No plan to have a child in 5 years" was a little higher than those who don't state their future child plan.19 of the 100 resumes were callbacks, raising the callback rate to 19 percent. By the t-test of the two different groups' result, the p-value of the two statistical data was lower than 0.05 , which considered no significant difference between the two values. So, the conclusion was that it wasn't important for men to state their child plan in the future, for that both stating or without stating the callback rate remained high among the other categories. The resumes that were categorized into female and without the statement of "No plan to have a child in 5 years" received 12 callbacks only, which is significantly lower than any other categories in the experiment. There were significant differences between the female and male without the statement according to the t-test of the two results. This p-value $(<0.05)$ suggested that child planning is a vital influence of the result of women's employment in the labor force market. Those who do not have children are more frequently rejected, and this influence of babies affects women only but not men-because men needless maternity leaves nor maternity compensation. Such a consequence clearly reflected the gender bias in the modern labor force market, putting women into a status that is inferior to men. The last category's callback rate, the callback rate of women with the statement is 22 percent, which was obviously greater than those women who didn't state their children's plan. The significant difference between the women who state and didn't state their children plan existed, and the significant difference between women and men both stating without children plan didn't exist. This reveals that women's children plan has significant means in the job hunting, while between those who don't have children, the gender bias is a lot smaller.

Another possible result, which Figure 2 shows, is that the callback rate of females with the statement is a lot lower than the predicted, while others remain the same result. As a consequence, there might be significant differences between the female and male even when they both state without children at all. The alternative could happen because the companies could feel that the female who wrote this statement was just trying to fake a competitive edge among other females and choose to ignore the statement.

\section{callback numbers}

25

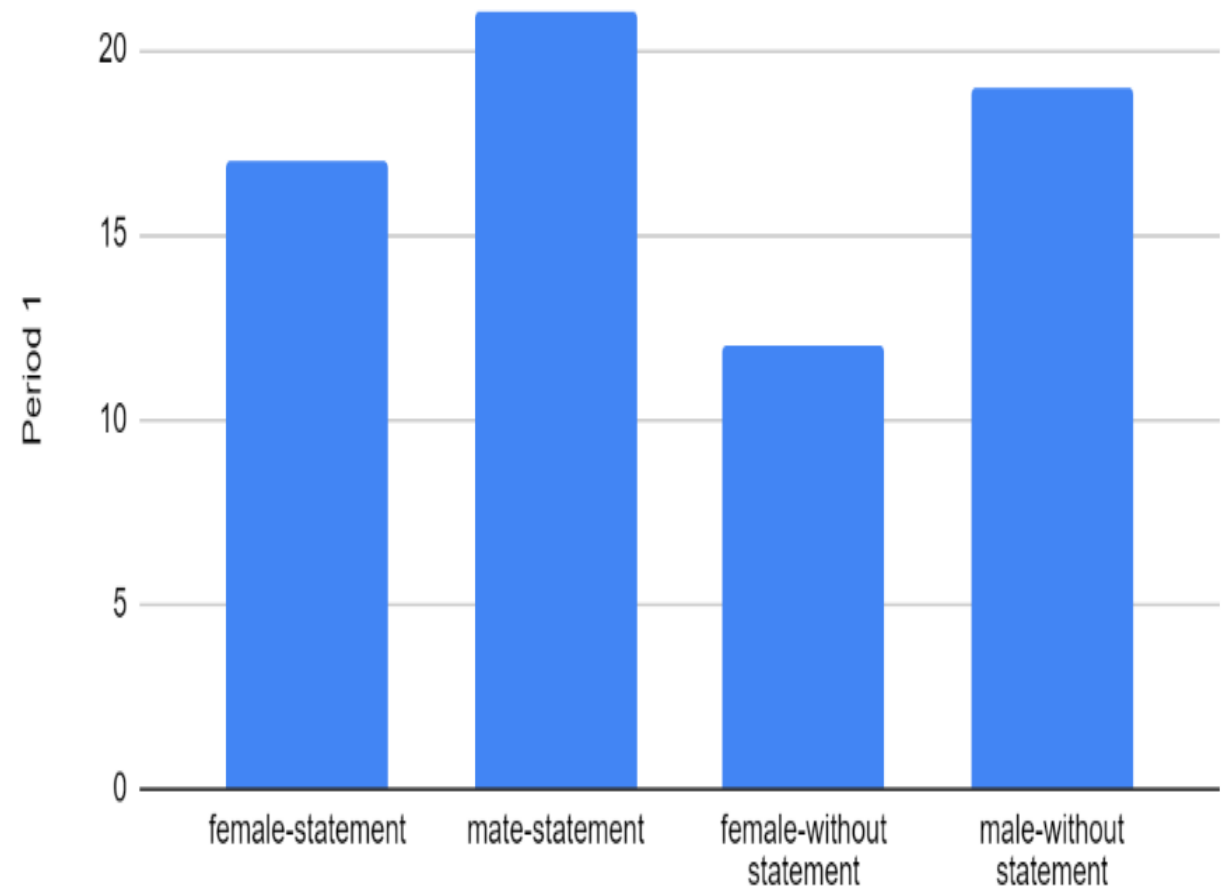

Figure 2 Predicted Result 2 


\section{CONCLUSION}

The experiment of course contains several limitations, including the sample size, target industry. But the obvious hiring bias between gender and children could pose severe threats to society. As more and more countries in the world are now suffering from an aging population, the policies of birth and retiring age are trying to make a difference on the topic. However, as long as the gender bias that relates to the children's plans still exists, the outcome of the policy is very likely to be unsatisfactory. Take China as an example, China has been publishing several laws on eliminating the birth limitations that were set in the early years due to the overfast population growth. Recently the three-children policy serves the function of slowing down the aging population just like the two-children policy published several years ago. There is a high possibility of the government being disappointed by the effect of the policy for this time_ once the news was posted and reported, the discussion on the internet is not supportive. More and more women are complaining that the policy is putting them into harder job hunting's compared to men at the same age. The existing hiring bias is seriously damaging the women's faith in having children. Who would still have children if it means that her career would be damaged and that she will forever stick to children and family work for the rest of her life like the women in the 1950s? The country should be aware of the women's situation and their struggle but continue to encourage giving birth to children without compensation. The country has to be aware, or the aging population won't slow down at all. There should be guarantees on women's rights in job hunting, whether they have or haven't any children plans. Only when children's plans are no longer a reason for hiring bias, can the women really be willing to give birth to children and the aging population can be relieved.

\section{REFERENCES}

[1]. What is Employment Discrimination? U.S. Equal Employment Opportunity Commission. (n.d.). https://www.eeoc.gov/youth/what-employmentdiscrimination.

[2]. Grant, S., \& Mizzi, T. (2014). Body Weight Bias in Hiring Decisions: Identifying Explanatory Mechanisms. Social Behavior and Personality: An International Journal, 42(3), 353-370. doi:10.2224/sbp.2014.42.3.353

[3]. Hildebrand, Kimberly D., "Using Independent Bernoulli Random Variables to Model Gender Hiring Practices" (2015). Student Research Submissions. https://scholar.umw.edu/student_research/33

[4]. Bosak, J., Sczesny, S. Gender Bias in Leader Selection? Evidence from a Hiring Simulation
Study. Sex Roles 65, 234-242 (2011). https://doi.org/10.1007/s11199-011-0012-7

[5]. Ratio of female to male labor force participation rate (\%) (modeled ILO estimate). Data. (n.d.). https://data.worldbank.org/indicator/SL.TLF.CAC T.FM.ZS.

[6]. Isaac, C., Lee, B., \& Carnes, M. (2009). Interventions That Affect Gender Bias in Hiring: A Systematic Review. Academic Medicine, 84(10), 1440-1446.

https://doi.org/10.1097/acm.0b013e3181b6ba00

[7]. Miller, M. (2013). WORKING WOMEN AND WORLD WAR II: . In N. Cott (Ed.), Volume 15 Women and War (pp. 402-421). Berlin, Boston: K. G.

Saur. https://doi.org/10.1515/9783110971125.402

[8]. BBC. (2021, August 20). China NPC: THREECHILD Policy formally passed into law. BBC News. https://www.bbc.com/news/world-asia-china58277473

[9]. Chen, W. (2021, May 14). China's aging POPULATION: Trends and policy response. CGTN. https://news.cgtn.com/news/2021-0514/China-s-aging-population-Trends-and-policyresponse-10fOOVvGufC/index.html.

[10]. Peng, A., Nushi, B., Kıcıman, E., Inkpen, K., Suri, S., \& Kamar, E. (2019). What You See Is What You Get? The Impact of Representation Criteria on Human Bias in Hiring. Proceedings of the AAAI Conference on Human Computation and Crowdsourcing, 7(1), 125-134. Retrieved from https://ojs.aaai.org/index.php/HCOMP/article/view 15281 